\title{
STRATEGI PENGEMBANGAN DAN PEMASARAN KOMODITAS KOPI DI DESA KAONGKE-ONGKEA KECAMATAN PASARWAJO
}

\author{
Wa Ode Al Zarliani ${ }^{1)}$ La Ode Muhammad Mustari' ${ }^{2)}$ \\ Program Studi Agribisnis \\ Fakultas Pertanian \\ Universitas Muhammadiyah Buton \\ Email: waodealzalian@yahoo.com
}

\begin{abstract}
The coffee development strategy in Kaongke-ongkea village is dominant in the valley area and is still limited to sloping areas. Although the water potential is very large, coffee processing in Kaongke-ongkea village is not yet electrically based. This is caused by undeveloped farmer institutions (BPTP Balitbang, Southeast Sulawesi, 2016). Facilities and infrastructure provide a very important role in supporting economic activities in the village of Kaongke-ongkea. The differences in the spatial patterns of land area, labor, production and farmer capital are very important. If this can be optimized, it can maximize greater profits for the Kaongke-ongkea Village in particularly and Pasarwajo Sub-district in generally. Aditional value of a commodity provides a very important role for regional economic growth so that in the development of an area it must pay attention to the issue because it can harm the regional economy (BendavidVal, 1991). The fundamental thing besides marketing aspect is the large transportation costs incurred by coffee farmers due to the long distance from the coffee plantation to the market. Differences in the distribution of coffee commodities in various locations cause costs (Rustiadi et al. 2011). The pattern of the distribution of the amount of income and the level of knowledge of coffee processing has an impact on the pattern of demand for coffee commodities. These differences in spatial patterns make inter-regional linkages very important for the stability of the economy of Kaongke-ongkea Village. In addition, the type of coffee industry tree character needs to be known in determining the extent of farmers' knowledge and technology used in coffee processing so that the added value of coffee from Kaongke-ongkea Village can be increased to certified processing (brand). Coffee producers certify products to increase the added value of coffee so that the character of the authenticity of the product based on its origin can be maintained (Botelho et al. 2017).
\end{abstract}

Keywords: Development strategy, coffee, marketing, SWOT

\begin{abstract}
Abstrak
Strategi pengembangan kopi di Desa Kaongke-ongkea dominan di daerah lembah dan masih terbatas pada daerah berlereng. Walaupun potensi air sangat besar, pengolahan kopi di Desa Kaongke-ongkea belum berbasis elektrik. Hal ini disebabkan oleh kelembagaan petani yang belum berkembang (BPTP Balitbang, Sulawesi Tenggara, 2016). Sarana dan prasarana memberikan peran yang sangat penting dalam menunjang kegiatan ekonomi di Desa Kaongkeongkea. Perbedaan pola spasial luas lahan, tenaga kerja, produksi dan modal petani sangat penting. Jika hal tersebut dapat optimal, maka dapat memaksimumkan profit yang lebih besar untuk Desa Kaongke-ongkea khususnya dan Kecamatan Pasarwajo pada umumnya. Nilai tambah dari suatu komoditas memberikan peran yang sangat penting bagi pertumbuhan ekonomi wilayah sehingga dalam pembangunan suatu wilayah harus memperhatikan isu
\end{abstract}


tersebut karena dapat merugikan perekonomian wilayah (Bendavid-Val, 1991). Hal yang mendasar selain aspek pemasaran adalah besarnya biaya transportasi yang dikeluarkan oleh petani kopi diakibatkan jarak yang jauh dari kebun kopi menuju pasar. Perbedaan sebaran komoditas kopi di berbagai lokasi menimbulkan cost (Rustiadi et al. 2011). Pola penyebaran jumlah pendapatan dan tingkat pengetahuan pengolahan kopi berdampak pada pola permintaan terhadap komoditas kopi. Perbedaan pola spasial ini menyebabkan keterkaitan antar wilayah menjadi sangat penting untuk stabilitas perekonomian Desa Kaongke-ongkea. Selain itu, jenis karakter pohon industri kopi perlu diketahui dalam menentukan sejauh mana tingkat pengetahuan petani dan teknologi yang digunakan terhadap pengolahan kopi sehingga nilai tambah dari kopi Desa Kaongke-ongkea dapat ditingkatkan sampai pengolahan yang tersertifikasi (brand). Produsen kopi melakukan sertifikasi produk untuk meningkatkan nilai tambah kopi sehingga karakter dari keaslian produk berdasarkan asalnya bisa terjaga (Botelho et al. 2017).

Kata kunci: Strategi pengembangan, kopi, pemasaran, SWOT

\section{PENDAHULUAN}

Pengembangan kopi Desa Kaongke-ongkea dominan di daerah lembah dan masih terbatas pada daerah berlereng. Walaupun potensi air sangat besar, pengolahan kopi di Desa Kaongkeongkea belum berbasis elektrik. Hal ini disebabkan oleh kelembagaan petani yang belum berkembang (BPTP Balitbangtan Sulawesi Tenggara, 2016). Sarana dan prasarana memberikan peran yang sangat penting dalam menunjang kegiatan ekonomi di Desa Kaongke-ongkea. Perbedaan pola spasial luas lahan, tenaga kerja, produksi dan modal petani sangat penting. Jika hal tersebut dapat optimal, maka dapat memaksimumkan profit yang lebih besar untuk Desa Kaongke-ongkea khususnya dan Kecamatan Pasarwajo pada umumnya.

Nilai tambah dari suatu komoditas memberikan peran yang sangat penting bagi pertumbuhan ekonomi wilayah sehingga dalam pembangunan suatu wilayah harus memperhatikan isu tersebut karena dapat merugikan perekonomian wilayah (Bendavid-Val, 1991). Hal yang mendasar selain aspek pemasaran adalah besarnya biaya transportasi yang dikeluarkan oleh petani kopi diakibatkan jarak yang jauh dari kebun kopi menuju pasar. Perbedaan sebaran komoditas kopi di berbagai lokasi menimbulkan cost (Rustiadi et al. 2011). Pola penyebaran jumlah pendapatan dan tingkat pengetahuan pengolahan kopi berdampak pada pola permintaan terhadap komoditas kopi. Perbedaan pola spasial ini menyebabkan keterkaitan antar wilayah menjadi sangat penting untuk stabilitas perekonomian Desa Kaongke-ongkea. Selain itu, jenis karakter pohon industri kopi perlu diketahui dalam menentukan sejauh mana tingkat pengetahuan petani dan teknologi yang digunakan terhadap pengolahan kopi sehingga nilai tambah dari kopi Desa Kaongke-ongkea dapat ditingkatkan sampai pengolahan yang tersertifikasi (brand). Produsen kopi melakukan sertifikasi produk untuk meningkatkan nilai tambah kopi sehingga karakter dari keaslian produk berdasarkan asalnya bisa terjaga (Botelho et al. 2017).

Pengembangan komoditas kopi sebagai komoditas unggulan daerah sangat penting dalam rangka meningkatkan produktivitas dan daya saing. Oleh karena itu, dukungan politis pemerintah daerah sangat diperlukan dalam pengembangan komoditas kopi melalui berbagai regulasi yang diarahkan untuk menciptakan berbagai bentuk kemudahan bagi kegiatan agribisnis yang diharapkan dapat mendongkrak daya saing komoditas. Selain itu upaya meningkatkan partisipasi seluruh pemangku kepentingan terus dilakukan baik pemerintah, masyarakat maupun swasta untuk aktif terlibat. Upaya-upaya ini harus dilakukan secara 
kontinyu mengingat komoditi tersebut memiliki peran strategis dalam pembangunan perekonomian daerah Kabupaten Buton selama ini yaitu tidak hanya berperan dalam memberikan pendapatan daerah, tetapi juga mampu membuka peluang kerja, meningkatkan pendapatan dan kesejahteraan masyarakat.

Adapun tujuan penelitian ini adalah sebagai berikut: 1) Untuk mengetahui strategi pengembangan kopi di Desa Kaongke-ongkea. 2) Untuk mengetahui strategi pemasaran komoditas kopi di Desa Kaongke-ongkea.

\section{METODE PENELITIAN}

Metode penentuan sampel petani kopi di Desa Kaongke-ongkea Kecamatan Pasarwajo Kabupaten Buton dilakukan dengan metode Simple Random Sampling dengan memilih 30 petani kopi secara acak sebagai sampel dari 120 petani kopi sebagai populasi. Besar sampel tersebut dianggap mewakili populasi. Penentuan besar sampel yang hanya 30 pengrajin bertujuan untuk mempermudah dan mempercepat proses penelitian (Singarimbun dan Effendi, 1989). Sedangkan Sampel pedagang adalah orang-orang yang terlibat dalam mendistribusikan kopi hasil produksi pengrajin hingga ke konsumen akhir. Pedagang perantara ditentukan dengan metode penelusuran (snowball sampling) yaitu dengan menelusuri semua pedagang yang terlibat dan yang mengambil kopi hasil produksi pengrajin sampel di Desa Kaongkeongkea Kecamatan Pasarwajo mulai dari pedagang pengumpul, pedagang besar dan pedagang pengecer.

Variabel yang diamati dalam penelitian ini yaitu: 1) Identitas responden adalah sebagai berikut: pendidikan, pengalaman berusaha, dan jumlah tanggungan keluarga; 2) Kondisi sosial ekonomi; 3) Jumlah produksi dan pendapatan; 4) Faktor internal strategi pengmebangan kopi, yaitu kekuatan (strength) dan kelemahan (weakness), dan faktor eksternal usaha rumah tangga kasoami, yaitu peluang (Opportunities) dan ancaman (threat).

Indikator kekuatan yang digunakan adalah: produk berkualitas, produk sehat, cita rasa disukai, harga di pasar bersaing, produk tanpa bahan pengawet makanan, lokasi usaha rumah tangga kasoami strategis, modal sendiri, dan bahan baku mudah didapatkan. Dan indikator Kelemahan meliputi: tidak memiliki sistem manajemen usaha rumah tangga kasoami, sedikitnya variasi bentuk dan cita rasa produk, minimnya kegiatan promosi, wilayah distribusi masih terbatas, minimnya modal yang dimiliki, kapasitas produksi masih terbatas, minimnya sarana dan prasarana operasional usaha rumah tangga kasoami, dan tidak adanya riset dan pengembangan produk.

Indikator kekuatan meliputi: mempunyai brand Image, yaitu nama yang sudah di kenal sebagai penghasil olahan kopi yang baik, sehat dan berkualitas, Melakukan pembinaan kepada petani di beberapa desa binaan, Kinerja sumber daya manusia yang baik, Harga minuman kopi relatif lebih murah, Memiliki lahan kopi sendiri seluas \pm 2 ha dan Sumber daya alam yang berkualitas. Indikator kelemahan meliputi: Mesin pengupas biji kopi memiliki kebisingan yang tinggi dalam sebuah ruangan, belum adanya organisasi yang mengatur sumber daya manusia, belum ada SOP (Standard Operational Procedure) tertulis untuk pekerja dan proses pengolahan kopi, kurangnya akses media sosial dalam promosi, tempat pengolahan masih tergolong kecil dan sederhana, proses produksi masih dilakukan pada satu ruang yang sama, belum ada label halal, pencantuman tanggal kadaluarsa masih manual, promosi masih terbatas, branding masih lemah, packaging masih belum sempurna dan keterbatasan modal untuk pengembangan usaha. Indikator peluang meliputi perkembangan konsumsi kopi yang meningkat dan perkembangan usaha minuman berbahan dasar kopi dan usaha kafe meningkat. 
Indikator ancaman meliputi kompetitor yang sudah ada dan terus bermunculan, harga penjualan produk competitor dan konsumen makin kritis terhadap kualitas produk

Data yang telah dikumpulkan di lapangan diolah dengan mentabulasikan dan seterusnya dipindahkan kedalam bentuk tabularis sesuai dengan kebutuhan, kemudian ditabulasi dan dianalisa dengan menggunakan analisis deskriptif dan analisis SWOT. Dengan analisis SWOT diharapkan dapat membantu mengatasi kelemahan dan ancaman, serta memaksimalkan kekuatan yang ada. Kekuatan yang dimiliki akan mampu memanfaatkan peluang pasar (Bradford, Duncan, dan Tarcy, 2004).

\section{HASIL DAN PEMBAHASAN}

\section{A. Alternatif Strategi Hasil Analisis dengan Analisis SWOT}

Dengan dilakukannya strategi menggunakan analisis SWOT maka petani Kopi Kaongkea-Ongkea dapat mengambil keputusan yang sifatnya stratejik, sebagai keputusan yang stratejik maka harus dilakukan analisis yang mendetail tentang usaha kopi Kaongkea-Ongkea sehingga mendapatkan titik temu antara faktor-faktor lingkungan internal dan faktor-faktor lingkungan eksternal dengan menghubungkan kedua faktor tersebut maka suatu tujuan dan sasaran dapat dicapai.

Faktor-faktor yang telah diidentifikasi dalam analisis SWOT, kemudian disusun ke dalam matriks SWOT. Faktor-faktor tersebut mewakili kondisi internal dan eksternal petani kopi Kaongke-Ongkea. Berdasarkan hasil diskusi dengan manajerial Kopi Kaongke-Ongkea setelah melihat kondisi internal dan eksternal tersebut, dirumuskan beberapa alternatif strategi yang diharapkan dapat diimplementasikan pada petani kopi Kaongkea-Ongkea untuk meningkatkan kinerja mereka. Alternatif strategi yang dapat diambil oleh Kopi Kaongke-Ongkea adalah sebagai berikut.

Berdasarkan Tabel 1 terdapat empat macam strategi yang dapat digunakan berdasarkan kondisi eksternal dan internal pengrajin yaitu SO (Strength-Opportunity), WO (WeaknesessOpportunity), ST (Strength-Threat), dan WT (Weaknesess-Threat). Berikut merupakan penjelasan alternatif-alternatif strategi pada masing-masing strategi:

\section{Strategi SO}

1. Membentuk tim R\&D (Reasearch and Development) untuk pengembangan produk inovatif dan kompetitif. R\&D dapat membantu petani kopi dengan melakukan pengembangan produk, sehingga konsumen tidak bosan. R\&D juga dapat menemukan produk yang sesungguhnya diinginkan oleh konsumen karena keinginan konsumen yang berubah-ubah sesuai dengan perkembangan zaman.

2. Meningkatkan produksi dan pemasaran dengan menambah variasi kopi dan memvariasi harga berdasarkan kemasan yang ada. Melihat kondisi pasar yang terus meningkat jumlahnya, pengrajin dapat melakukan peningkatan kegiatan produksi agar memiliki stok yang cukup untuk memenuhi kebutuhan pasar. Kegiatan pemasaran juga harus diperluas untuk meningkatkan peluang produk dikonsumsi oleh konsumen. Perluasan target pemasaran dapat dilakukan dengan bantuan media sosial maupun pemasaran secara langsung ke pembeli seperti kafe-kafe atau dalam sebuah bazar maupun acara-acara lain.

3. Memperbanyak petani binaan. Memperbanyak pembinaan kepada petani dapat meningkatkan produktivitas dan juga menjaga kualitas hasil kopi yang dibutuhkan pengrajin.

4. Menambah tenaga ahli. Penambahan tenaga ahli dapat membantu pengrajin dalam mengontrol kualitas produk yang dihasilkan. Tenaga ahli juga dapat berperan dalam peningkatan kualitas produk agar lebih baik. 


\section{Strategi WO}

1. Melakukan penetapan SOP untuk setiap proses pengolahan dan pekerjanya. SOP dapat membantu pekerja baru dalam menjalankan tugas yang diberikan oleh pengrajin. SOP juga dapat menjaga pekerjaan yang dilakukan oleh pekerja efektif dan efisien sehingga dapat mencapai target jumlah dan kualitas yang ditetapkan perajin.

2. Pengembangan kinerja mesin untuk keamanan para pekerja. Mesin yang baik dapat menghasilkan produk yang baik, semakin baik kinerja mesin maka produk yang dihasilkan juga akan semakin baik dari segi kualitas dan kuantitasnya. Pemilihan mesin yang digunakan juga harus memperhatikan pekerja mesin tersebut. Pekerja yang menjalakan mesin harus diperhatikan keamanannya agar tetap dapat melakukan pekerjaannya dengan baik dan tidak merugikan pengrajin. Apabila pekerja tersebut sakit dan memerlukan perawatan maka pengrajin akan rugi karena kehilangan pekerjanya dan pemilik usaha akan mengeluarkan biaya tambahan untuk pengobatan pekerjanya.

\section{Strategi ST}

1. Mengutamakan kualitas produk sebagai daya saing. Kualitas produk merupakan keunggulan yang dapat digunakan pengrajin dalam bersaing di pasar. Kualitas produk merupakan keunggulan komparatif yang tidak dimiliki pengrajin lain, sehingga dapat dijadikan keunggulan dalam bersaing dengan produk lain.

2. Menjaga stabilitas harga jual produk. Strategi ini dilakukan untuk menjaga kepercayaan konsumen dalam membeli produk, karena harga akan berbanding lurus dengan kualitas.

\section{Strategi WT}

1. Menekan biaya produksi dengan melakukan efisiensi di setiap proses pengolahan. Efisiensi yang dilakukan dapat berupa implementasi prinsip produksi bersih yaitu dengan meminimalisir limbah hasil produksi. Menggunakan mesin dan kebutuhan lain yang sesuai juga dapat memotong biaya produksi sehingga tidak ada biaya yang terbuang percuma seperti penggunaan mesin diatas kapasitas yang dibutuhkan.

2. Melakukan promosi atau potongan harga produk dan kerja sama untuk mengembangkan kafe yang dikelola. Strategi ini dapat dilakukan untuk menarik pelanggan baru agar membeli produk. Promosi juga dapat dilakukan untuk menjaga pelanggan lama agar tetap membeli produk pengrajin. Pemberian diskon dalam periode tertentu juga dapat mengurangi stok lama agar habis dan tidak tersimpan percuma. Kerja sama dengan pengrajin lain juga dapat menjadi alternatif strategi agar perusahan dapat memunculkan hal baru tanpa melakukan aktivitas R\&D seperti kerja sama dengan produk makanan atau minuman lain untuk ditempatkan di kafe. Kerja sama juga dapat dilakukan dengan usaha dibidang lain yang dapat dikolaborasikan dengan kafe tersebut seperti penampilan musik, acara "nobar" dengan penggemar sepakbola dan lain-lain. 
Tabel 1. Matriks Strategi Hasil Analisis SWOT Strategi Pengmebangan Kopi di Desa Kaongke-ongkea Kecamatan Pasarwajo Kabupaten Buton

\begin{tabular}{|c|c|c|}
\hline Eksternal & \begin{tabular}{|l} 
Weaknesses \\
1. \\
Mesin pengupas biji kopi \\
menimbulkan kebisingan \\
yang tinggi dalam sebuah \\
ruangan \\
2. Belum adanya organisasi \\
yang mengatur sumber \\
daya manusia \\
3. $\begin{array}{l}\text { Belum ada SOP tertulis } \\
\text { untuk pekerja dan proses }\end{array}$ \\
pengolahan kopi \\
4. $\begin{array}{l}\text { Kurangnya akses media } \\
\text { sosial dalam promosi. }\end{array}$ \\
5. Tempat pengolahan masih \\
tergolong kecil dan \\
sederhana. \\
6. Proses produksi masih \\
dilakukan pada satu ruang \\
yang sama \\
7. $\begin{array}{l}\text { Belum ada label halal } \\
\text { 8. Pencantuman tanggal } \\
\text { kadaluarsa masih manual }\end{array}$
\end{tabular} & $\begin{array}{l}\text { Strength } \\
\text { 1. Kopi Kaongke-Ongkea } \\
\text { merupakan kopi sehat dan } \\
\text { berkualitas } \\
\text { 2. Memiliki beberapa petani } \\
\text { binaan di desa penghasil } \\
\text { kopi } \\
\text { 3. Memiliki sumber daya } \\
\text { manusia yang baik } \\
\text { 4. Harga minuman kopi relatif } \\
\text { lebih murah } \\
\text { 5. memiliki lahan kopi sendiri } \\
\text { seluas } \pm 2 \text { ha } \\
\text { 6. Sumber daya alam yang } \\
\text { berkualitas }\end{array}$ \\
\hline $\begin{array}{l}\text { Opportunity } \\
\text { 1. } \text { Perkembangan } \\
\text { konsumsi kopi yang } \\
\text { meningkat } \\
\text { 2. Perkembangan usaha } \\
\text { minuman berbahan } \\
\text { dasar kopi dan usaha } \\
\text { kafe }\end{array}$ & $\begin{array}{l}\text { Strategi WO } \\
\text { 1. Melakukan penetapan SOP } \\
\text { untuk setiap proses } \\
\text { pengolahan dan pekerjanya } \\
\text { 2. Pengembangan kinerja } \\
\text { mesin untuk keamanan para } \\
\text { pekerja }\end{array}$ & $\begin{array}{l}\text { Strategi SO } \\
\text { 1. Memiliki tim R\&D untuk } \\
\text { pengembangan produk } \\
\text { inovatif dan kompetitif } \\
\text { 2. Meningkatkan produksi dan } \\
\text { pemasaran dengan } \\
\text { menambah variasi kopi dan } \\
\text { memvariasi harga } \\
\text { berdasarkan kemasan yang } \\
\text { ada }\end{array}$ \\
\hline \begin{tabular}{|l} 
Threat \\
1. Kompetitor yang \\
sudah ada dan terus \\
bermunculan \\
2. Harga penjualan \\
produk kompetitor
\end{tabular} & \begin{tabular}{|l} 
Strategi WT \\
1. Menekan biaya produksi \\
dengan melakukan efisiensi \\
di setiap proses pengolahan \\
2. Melakukan promosi atau \\
potongan harga produk dan \\
kerjasama untuk \\
mengembangkan kafe yang \\
dikelola
\end{tabular} & \begin{tabular}{|l} 
Strategi ST \\
1. $\begin{array}{l}\text { Mengutamakan kualitas } \\
\text { produk sebagai daya saing } \\
\text { 2. } \\
\text { Menjaga tingkat harga yang } \\
\text { kompetitif }\end{array}$ \\
\end{tabular} \\
\hline
\end{tabular}


Media Agribisnis

Vol. 4, Issue 1, Mei 2020

P-ISSN: 2527-8479 E-ISSN: 2686-2174

Tabel 2. Analisis SWOT kuantitatif kondisi internal Petani Kopi

\begin{tabular}{|c|c|c|c|c|}
\hline & Pernyataan & Bobot Relatif & $\begin{array}{l}\text { Rata-Rata } \\
\text { Rating }\end{array}$ & Skor \\
\hline & Strength & & & \\
\hline S1 & Kopi Kaongke-Ongkea merupakan kopi sehat dan berkualitas & 0,06 & 3,73 & 0,22 \\
\hline $\mathrm{S} 2$ & Melakukan pembinaan kepada petani di beberapa desa binaan & 0,04 & 2,97 & 0,12 \\
\hline S3 & Kinerja sumber daya manusia yang baik & 0,08 & 3,6 & 0,29 \\
\hline S5 & Harga minuman kopi relatif lebih murah & 0,05 & 3,57 & 0,18 \\
\hline S6 & memiliki lahan kopi sendiri seluas \pm 2 ha & 0,06 & 3,3 & 0,20 \\
\hline S7 & $\begin{array}{l}\text { Sumber daya alam yang berkualitas } \\
\text { Weaknesess }\end{array}$ & 0,01 & 2,83 & 0,03 \\
\hline W1 & $\begin{array}{l}\text { Mesin pengupas biji kopi memiliki kebisingan yang tinggi dalam sebuah } \\
\text { ruangan }\end{array}$ & 0,04 & 2,5 & 0,10 \\
\hline W2 & Belum adanya organisasi yang mengatur sumber daya manusia & 0,07 & 3,5 & 0,25 \\
\hline W3 & Belum ada SOP tertulis untuk pekerja dan proses pengolahan kopi & 0,05 & 2,75 & 0,14 \\
\hline W4 & Kurangnya akses media sosial dalam promosi. & 0,06 & 2,07 & 0,12 \\
\hline W5 & Tempat pengolahan masih tergolong kecil dan sederhana. & 0,08 & 3,7 & 0,30 \\
\hline W6 & Proses produksi masih dilakukan pada satu ruang yang sama & 0,07 & 3,4 & 0,24 \\
\hline W7 & Belum ada label halal & 0,07 & 3 & 0,21 \\
\hline W8 & Pencantuman tanggal kadaluarsa masih manual & 0,05 & 3,2 & 0,16 \\
\hline W9 & Promosi masih terbatas & 0,1 & 2,83 & 0,28 \\
\hline W10 & Branding masih lemah & 0,04 & 3,3 & 0,13 \\
\hline W11 & Packaging masih belum sempurna & 0,04 & 3,2 & 0,13 \\
\hline \multirow[t]{3}{*}{ W12 } & Keterbatasan modal untuk pengembangan usaha & 0,03 & 3,5 & 0,11 \\
\hline & Total & 1 & & 3,21 \\
\hline & Total nilai Strength-Weaknesess & & & $-1,13$ \\
\hline
\end{tabular}




\section{Media Agribisnis}

Vol. 4, Issue 1, Mei 2020

\section{P-ISSN: 2527-8479 E-ISSN: 2686-2174}

Tabel 3. Analisis kuantitatif SWOT kuantitatif kondisi eksternal petani kopi Kaongke-Ongkea

\begin{tabular}{|c|c|c|c|c|}
\hline & Pernyataan & $\begin{array}{l}\text { Bobot } \\
\text { Relatif }\end{array}$ & $\begin{array}{l}\text { Rata-Rata } \\
\text { Rating }\end{array}$ & Skor \\
\hline & \multicolumn{4}{|l|}{ Opportunity } \\
\hline $\mathrm{O} 1$ & Perkembangan konsumsi kopi yang meningkat & 0,22 & 3,5 & 0,77 \\
\hline $\mathrm{O} 2$ & $\begin{array}{l}\text { Perkembangan usaha minuman berbahan dasar kopi dan usaha kafe } \\
\text { Threat }\end{array}$ & 0,19 & 3,5 & 0,67 \\
\hline T1 & Kompetitor yang sudah ada dan terus bermunculan & 0,21 & 2,83 & 0,59 \\
\hline $\mathrm{T} 2$ & Harga penjualan produk kompetitor & 0,21 & 3,25 & 0,68 \\
\hline \multirow[t]{3}{*}{$\mathrm{T} 3$} & Konsumen makin kritis terhadap kualitas produk & 0,17 & 3,4 & 0,58 \\
\hline & Total & 1 & & 3,29 \\
\hline & Total nilai Opportunity-Threat & & & $-0,41$ \\
\hline
\end{tabular}




\section{KESIMPULAN DAN SARAN}

\section{Kesimpulan}

Adapun kesimpulan yang dapat diambil dari pembahasan penelitian ini adalah sebagai berikut

1. Hasil analisis SWOT kuantitatif menunjukkan bahwa petani kopi Kaongke-Ongkea berada pada kuadran IV yaitu pada titik $(-1,13 ;-0,41)$, dimana petani kopi berada pada posisi yang dilematis. Strategi bertahan harus dilakukan untuk membenahi kondisi internal pengrajin agar tidak semakin terperosok. Petani kopi harus melakukan strategi WT yaitu 1) Menekan biaya produksi dengan melakukan efisiensi di setiap proses pengolahan; 2) Melakukan promosi atau potongan harga produk dan kerja sama untuk mengembangkan kafe yang dikelola.

2. Hasil analisis data nilai faktor internal yaitu $-1,13$, didapat dari total penjumlahan rating dikalikan bobot faktor kekuatan dengan kelemahan Petani kopi KaongkeOngkea, nila kekuatan yang paling tinggi ada di poin "Kinerja sumber daya manusia yang baik".

3. Nilai kelemahan paling tinggi terdapat pada poin "Tempat pengolahan masih tergolong kecil dan sederhana". Menunjukan bahwa tempat Petani kopi KaongkeOngkea tergolong kecil dan sederhana.

4. Hasil analisi dari nilai faktor eksternal yaitu $-0,41$, didapat dari total penjumlahan rating dikalikan bobot faktor peluang dari ancaman pengrajin. Nilai peluang paling tinggi terdapat pada poin "Perkembangan konsumsi kopi yang meningkat". Menunjukkan tingginya trend masyarakat untuk mengkonsumsi kopi sebagai minuman santai.

5. Nilai ancaman paling tinggi terdapat pada poin "Harga penjualan produk kompetitor" menunjukkan Petani kopi Kaongke-Ongkea harus selalu mempunyai strategi-strategi jitu yang dalam menjual produk dengan harga bersaing.

\section{Saran}

Dan untuk hal ini juga dibutuhkan peran pemerintah daerah lebih besar lagi terutama Dinas Pertanian dan Perdagangan untuk memberikan bantuan berupa kebijakankebijakan yang mampu melindungi pertumbuhan pengrajin kopi dan merangsang mereka untuk mampu bersaing lebih baik lagi, misalnya dengan hibah alat pengemasan dan mempromosikan kopi Koangke-Ongkea ke masyarakat nasional..

\section{DAFTAR PUSTAKA}

Bendavid-Val, A. 1991. Regional and Local Economic Analysis for Practitioners Fourth Edition. London, Pr.

Botelho BG, Oliveira LS, Franca AS. 2017. Fluorescence spectroscopy as tool for the geographical discrimination of coffee produced in different regions of minas gerais state in Brazil. Journal Food Control.

Bradford, R.W., P.J. Duncan, and B. Tarcy. 2000. Simplified Strategic Planning: A NoNonsense Guide for Busy People Who Want Result Fast! www.quickmba.com/strategy/swot/

Bratakusumah, D.S., Riyadi. 2003. Perencanaan Pembangunan Daerah. Jakarta: PT. Gramedia Pustaka Utama. 
Danarti dan Najiyati.S. 2004 .Budidaya Tanaman Kopi dan Penanganan Pasca Panen. Penebar Swadaya. Jakarta.

Prasetio, 2019. Kopi Khas Buton Miliki Cita Rasa Tersendiri di Mata Dunia, La Bakry: Kita Berusaha Kopi Khas Buton Dapat Hak Intelektual dari Dunia. https://baubaupost.com/2019/03/10/kopi-khas-buton-miliki-cita-rasa-tersendiri-dimata-dunia-la-bakry-kita-berusaha-kopi-khas-buton-dapat-hak-intelektual-daridunia/

Rahardjo, Pudji. 2012. Panduan Budidaya dan Pengolahan Kopi Arabika dan Robusta. Penebar Swadaya. Jakarta.

Rangkuti, F. 2006. Analisis SWOT: teknik membedah kasus bisnis.Gramedia Pustaka Utama. Jakarta

Rustiadi E. Saefulhakim S. Panuju DR 2011. Perencanaan dan Pengembangan Wilayah. Jakarta (ID): Crestpent Press dan Yayasan Obor Indonesia

Singarimbun, M dan S. Effendi. 1989. Metode Penelitian Survei. Jakarta: PT. Pustaka LP3ES Indonesia.

Yusdiali, W. 2008. Pengaruh Suhu dan Lama Penyaringan terhadap Tingkat Kadar Air dan Keasaman Kopi Robusta (Coffee of Robusta). Disertasi. Universitas Hasanuddin. Makasar. 